\title{
Trends of Risk and Security Problems for States and Emerging Strategies for Coping with those Trends
}

\author{
by Robert Ellsworth
}

When one considers very carefully the risk and security problems that states face today, and then looks at how states are attempting to cope with those problems, one is almost forced to the old definition of strategy as: "When you have run out of bullets, how to keep on firing."

\section{Introduction}

We live today in an "Age of Peace". What does one mean by that phrase - an age of peace? It is surely something different from the condition of having recently recovered from a war, or getting ready to fight the next war, which are the conditions that most of mankind has been in for most of history. In an age of peace, on the other hand, there is no war or prospect of war, between the major powers, of the kind which the powers maintain their main forces to fight. There have been a few periods like this in recent history : after the Napoleon period, there was a wide-spread determination in Europe never to let anything like that happen again. After World War I, which was rhetorically " the war to end all wars", there was a wide-spread determination not to have any more war. Ages of peace don't rule out revolutions, or wars with lesser powers, but the age of peace which we have enjoyed for about 30 years is different. It's unique in two respects : first, in the length of time it's lasted; and secondly the intensity and the wide-spread scope of the feeling that a war between the major powers, with the strategic nuclear weapons that they maintain, is absolutely unthinkable. So that we do live in a unique age of peace.

And of course the first great risk for states is the risk of the collapse of that condition.

Another great set of risks that we face today - as states and as peoples - is the risks that come from an apparent global shortage of material resources. The energy crisis is one example. There are a number of other examples and we will examine some of them. There is a specific risk in the build-up of military forces on the part of the Soviet Union. Not just in the strategic nuclear realm, but also in their deployments in Europe, in terms of their naval build-up and deployments, in their capabilities for projecting and exercising power beyond Eurasia, and in their utilisation of modern technology.

There are, in a general sense, two other kinds of risks that states face today. On the one hand, there is always the risk of being taken by surprise. In military history one is familiar with the surprises that have been visited on various states: Operation Barbarossa, the German invasion of Russia in June 1941 ; Pearl Harbour, the Japanese attack on the United States in December of that year; and in the Middle East the Israeli attack on Egypt in June 1967 and the Egyptian attack on the Sinai in October 1973. 
Also in the non-military field, states were taken quite by surprise in October 1973 by the oil embargo, and during that winter by the $400 \%$ increase in crude oil prices suddenly imposed by OPEC. What happens is that states decline to look at signs which, in retrospect, are always said to have been quite visible. States decline to see what is unpleasant for them to see, and they tend to get taken by surprise.

Contrarywise another risk is that states in contemplating the external world tend to exaggerate certain risks and therefore make unwise, and unnecessary concessions. For example in the case of the German re-occupation in the Rheinland in 1936 the Western powers exaggerated the risks of response if they offered resistance to the re-occupation of the Rheinland. In 1972, risks were exaggerated with the result that the United States conceded too much in the Interim Agreement covering Offensive Nuclear Weapons, in SALT I. That was corrected later at Vladivostok in 1974, but there is almost always the risk of exaggerating risks, and of making unnecessary and unwise concessions, or yielding unnecessarily, as a result.

\section{Oil pricing practices}

Let us look first at some of the specific risks involved in oil pricing practices : a problem with which all states are confronted today, not just the oil-consuming industrial states. The non-oil lesser developed countries have even worse problems coping with current oil pricing practices, and in my judgment the oil-producing states themselves have certain problems associated with the pricing practices that they are pursuing today.

For the last five years the lowest inflation rates in the industrial world have been well above what had been considered unacceptably high levels of inflation during the entire post World War II era. And then, there are the particular problems imposed on the industrial countries not just by the level of inflation, which is extremely high, but also by the fact that among different countries the rates are different. Within the OECD, for example, inflation rates today range between $5 \%$ in some countries to as high as $20 \%$ in other countries. That creates very great problems in trade, monetary policy, etc.

Unemployment is another high-risk condition which has been exacerbated by the oil pricing practices of the world today, and I need not say to this group that inflation and unemployment together have historically been the father of confrontation and upheaval and the grand-father of war.

A further very great risk stems from the fact that we are entrapped in a vicious circle. Whenever recovery commences in the industrial countries, that is used as a justification by the oil producing countries to increase their prices. That of course takes the edge off the recovery, reinstitutes conditions of virulent inflation and unemployment and calls forth measures to cope with those undesirable and risky conditions. It doesn't work. The world does not work today under the oil pricing practices currently being followed.

Here is a case where I think it's fair to say the strategies of states are largely an exercise in how to keep on firing after you have run out of bullets. No one today has any strategy for dealing directly with current oil pricing practices. Of course states are trying to sell goods to the oil producers to cope with balance of payments problems, taking certain modest measures of conservation, going into debt up to their eyeballs, or doing all of the above. But essentially there is no strategy today for dealing directly with oil pricing practices as such. 
The reason, or one of the reasons why this is so, is that economically recoverable oil exists only in limited quantities in the earth and that within a certain number of years it will be necessary to replace oil with alternative sources of energy. And in order to develop alternatives to oil as a source of energy it is necessary that oil prices be at something like their present levels. Still, there is some room for the exercise of strategy in this important area.

One of the partial alternatives to oil which creates some risks is nuclear energy. In 1973/74 the oil embargo and price rise gave a tremendous fillip to the development of nuclear energy in a number of states because for them there is absolutely no option other than nuclear power as a source of electricity. That created the virtual certainty within 10 years of very large amounts of plutonium (which is a nuclear explosive) in stockpiles all over the world in spent fuel from nuclear reactors. That - coupled with the nuclear explosion of India in May 1974 - regenerated the spectre of nuclear weapons proliferation on a world-wide basis, which was not a new concern but had been quiescent for a number of years. In addition, a number of industrial countries in the early 1970's had begun a spirited competition in the export of nuclear technology which must increase the risks of weapons proliferation.

There is now an effort by states to develop a strategy to cope; initial steps are being taken. In many cases those steps are a little bit stumbling. For example last week, on April 6th, President Carter made a statement in Washington aimed at the elimination of plutonium from the world economy. In order to induce states to forego access to plutonium, he alluded to the possibility of the United States supplying the world with enriched fuel so that the world could avoid reprocessing and the creation of free plutonium. To put it directly : President Carter has asked the world, as a part of a strategy to avoid the risks of nuclear weapons proliferation, to forego access to nuclear fuel except that which might be supplied by the U.S.A. That is not a viable basis for a widely shared or a long lasting international regime. Other steps will have to be taken to develop a strategy for dealing with the problem of proliferation as the world develops nuclear energy to substitute partially for oil.

\section{Global resource shortages}

The energy crisis, based as it is on the realization that there is a limited supply of economically recoverable oil available, is only one example of what many believe is a much wider problem : the risks of broad global resource shortages.

With regard to that problem there are two conflicting views. The "catastrophists" believe that the earth's resources will soon be exhausted, and the approach of this condition will lead to the collapse of society, including the end of the age of peace to which I referred at the beginning of my remarks.

The conflicting view, that of the "cornucopians", holds that most of the earth's essential raw materials are virtually infinite and that as we exhaust one raw material we will turn to inexhaustible substitutes. According to this view we will ultimately settle into a steady state of substitution and recycling of materials.

In order to bring a little perspective to these two conflicting views, it is useful to realize that $80 \%$ of all the molecules that we take out of the earth and use are fossil fuel. All our technological civilization, and especially our transportation, is based on an 
addiction to fossil fuel - an addiction that cannot be broken, or at least cannot be broken in the foreseeable future. That is a very special problem.

But the minerals that we depend upon - iron, aluminium, and copper - are present in very large quantities throughout the world and at high concentrations. For those elements like mercury or silver that are not so widely present there are in fact large possibilities for substitution. Therefore, the energy problem is different in degree to the extent that it is a different problem in kind. It is necessary not to confuse the two. Certainly there are great risks associated with both.

What are the risks? The present stage of the world, while we are using up fossil fuel at a terrific rate, may be called Stage I. Stage III, I see as the age of substitutability. The risks lie in developing appropriate strategies to get from Stage I to Stage III. So far the strategies that have been spoken about and attempted seem to be quite unadequate. First, it takes a long time to transition just in the case of energy : it took 60 years to transition from wood to coal, it took about the same period to transition from coal to oil and gas. As we look at strategies for transitionning from oil and gas to something else - it seems clear that rising environmental concerns, and shortages of capital, may stretch that process even further.

That risk is multiplied many times by the short time horizons of most government agencies and corporations responsible for resource policy. Decision-making in corporations is conditioned by interest rates which encourage indifference to costs and benefits that won't be realized within about five years. Inflation further shortens the time horizon. In the case of governments, the next election prevents most policies that could return great benefits over the long term, so that governments tend to have a short time horizon. Totalitarian and authoritarian governments do not seem to be doing much better, so I am not certain that the answer is the abandonment of democracy. There is no model anywhere in the world of a state dealing with the problem in a way that offers much help.

What are in fact the emerging strategies ? First, we see competition for access to oil.

\section{CHART I \\ ESTIMATED 1985 OPEC EXPORT LEVELS}

(in million barrels a day)

\section{ESTIMATED 1985 OECD IMPORT NEEDS}

(in million barrels a day)

\begin{tabular}{lcllc} 
Policy & Exports & & Assumption & Imports \\
\cline { 2 - 2 } Low & 29,9 & & High Growth & 38,8 \\
Medium-Low & 32,1 & & Medium Growth & 35,0 \\
Medium-High & 35,5 & Low Growth & 31,9 \\
High & 38,6 & Accelerated Policy & 24,3 \\
Source : OECD, World Energy & Outlook, & Source : Rustow, “ Foreign Affairs ", April \\
1977, pp 9, 91, 94-96. & & & 1977, p. 50q.
\end{tabular}

The possibility of there being a balance between OPEC's ability and willingness to provide oil to the world on the one hand, and the needs of the OECD countries for 
oil, on the other hand, is very slight. Unless we are very lucky indeed, the figures portend in fairly clear terms a major world crisis in the early or mid 1980's because of the fact that there may not be enough oil from OPEC to satisfy the needs of the OECD countries. This alarming situation assumes zero interest on the part of the Soviet Union in OPEC oil by 1985 . That is an assumption which appears to be quite optimistic inasmuch as the Soviets have their energy problem too. They are experiencing rising industrial and consumer demand for energy. They have great difficulties developing their energy resources in Sibiria. They have not been able to get the capital or the technology from the West. The U.S.S.R. therefore will turn more and more to the Gulf and Middle East for access to that low cost and easy to extract (though not low price) oil. Although the OPEC price is something over $\$ 11.00$ a barrel, it costs only about 29 cents a barrel to extract. The Soviets - I expect - will need oil from the Gulf and Middle East by 1985 to the tune of somewhere between 2 and 4 million barrels a day. That will cause horrendous problems for all of us : Europeans, Americans, Japanese, and Russians.

Competition for access, then, is one of the strategies that has begun to emerge for dealing with the energy crisis. There are also the beginnings of another strategy for dealing with the overall global resource shortage problem, and that strategy could be called the deliberate societal shift toward placing an intrinsic value on conservation, on low material and energy growth. This, perhaps, holds out considerable hope, for two reasons. First, it is only by having a set of values that one can develop a strategy : that is in fact what a strategy is. A strategy is basically a set of values that permits one to take a longer term view of matters - whatever those matters are - than would be dictated by short term tactical considerations. The emergence of a set of values, therefore, is a hopeful sign. Secondly major deliberate societal shifts in values of this kind can take place quickly -, have done so in the past. Between 1880 and 1900 in Europe a rapid and pervasive social change took place as nation after nation abandoned high rates of marital fertility and adopted contraception on a wide scale. As a result, in this short 20-year period there was a very great reduction in the birth rate in Europe as a deliberate internalisation of a set of values and therefore of a strategy. This was rather suggested not imposed by any corporation or government.

We cannot predict the future, but we can have value systems - a strategy - that will help us move from Stage I to Stage III. Those values would be a) conservation; b) efficiency and effectiveness in the transformation of raw resources into food, fertilizer, electricity, and machinery, placing a premium if you will on science and technology; $c$ ) cooperation instead of competition ; $d$ ) steadiness of purpose ; $e$ ) resilience in response to change. These are some of the characteristics and qualities of a viable strategy which can help us move from Stage I to Stage III without having a collapse of society, a termination of the age of peace.

\section{The Russian military build-up}

In the meanwhile however, we are confronted with the risks of a very substantial Russian build-up. For the last ten years, the Soviet Union has been adding between $3 \%$ and $4 \%$ a year, in real terms, to the resources devoted to military purposes. In 1972 those resources exceeded the comparable resources devoted to military purposes 
by the United States, and have exceeded the U.S. in every year since then. In 1976 the Soviets were spending, in real terms, $40 \%$ more on their military than the United States. As for the future effects of present spending, the U.S.S.R. has been spending on investment account - that is to say on procurement, and research and development - at a higher rate than the overall rate, i.e. at $4 \%$ p.a. This broadly based and persistent build-up poses three main risks :

1. It adds fuel to the competitive fires and works against cooperation, which was one of the qualities of Stage I - Stage III strategy which has been mentioned as highly desirable.

2. Because the facts of this Russian military build-up are quite unpleasant to contemplate, it may be overlooked or ignored in the wider world; that could lead to unpleasant surprises later on.

3. Or on the contrary the build-up can be exaggerated, as for example our own retired Major General Keegan has been exaggerating it by saying that the Russians are already superior to the United States. And that exaggeration could lead - if it became widely accepted - to unnecessary and unwise concessions in various political areas.

Let us look for a moment at some specific aspects of the build-up. In the strategic nuclear realm, the Soviets' build-up began after the Cuba Missile Crisis of 1962, some 15 years ago. But one of the most intensive periods of the Soviets' strategic nuclear build-up has taken place in the last 5 years : that is, since the 1972 SALT-I agreements. In that five-years period the Soviets have deployed three new land-based ICBM missiles and two new submarine-based ballistic missiles. All of the new missiles deployed since 1972 are equipped with multiple independently targeted re-entry vehicles (MIRV's). They have high throw-weights and they have been provided with warheads with increasing accuracy. Thus, the Russians have provided themselves in the last five years with a hard-target counterforce threat to the ICBM force of the United States; in addition they have under development one further land-based ICBM and two further submarinebased ICBM's. Moreover, they have deployed the Backfire bomber, and since 1971 have embarked on a very substantial programme of civil defence.

The result is that, between the United States and the Soviet Union, as far as strategic nuclear forces are concerned, a condition of rough equivalence now obtains. (See chart II). The chart shows trends over the last several years. It is a chart which indicates a US advantage, until about 1970 , in those static measures of the balance which are charted (it's been impossible to chart warhead accuracy): equivalent megatonnage, throw-weight, numbers of strategic nuclear delivery vehicles (which includes land-based ICBM, submarine-based ballistic missiles, and strategic bombers), and numbers of warheads. The Soviet Union has the advantage in 1977 in equivalent megatonnage because their land-based ICBM's have high throw-weight. They have a slight advantage in strategic nuclear delivery vehicles. In numbers of warheads the United States has an advantage. What does it mean? All of these things are so abstract.

It surely means something, though. One must recall, for example, the reaction of Mao-Tse-Tung in 1957 to the Russian sputnik. Mao took that as meaning the Soviets had missile superiority over the United States. He therefore asked Khrushchev for help in standing up to the United States over Quemoy and Matsu. Khrushchev refused, and 
that was one of the things which lead to the great schism between the Chinese and the Russians. One must also recollect the American presidential campaign of 1960 : the so-called missile gap. So, these things do have some kind of political meaning although in themselves they are quite abstract.

\section{CHART II}

US/USSR STRATEGIC FORCES ADVANTAGE

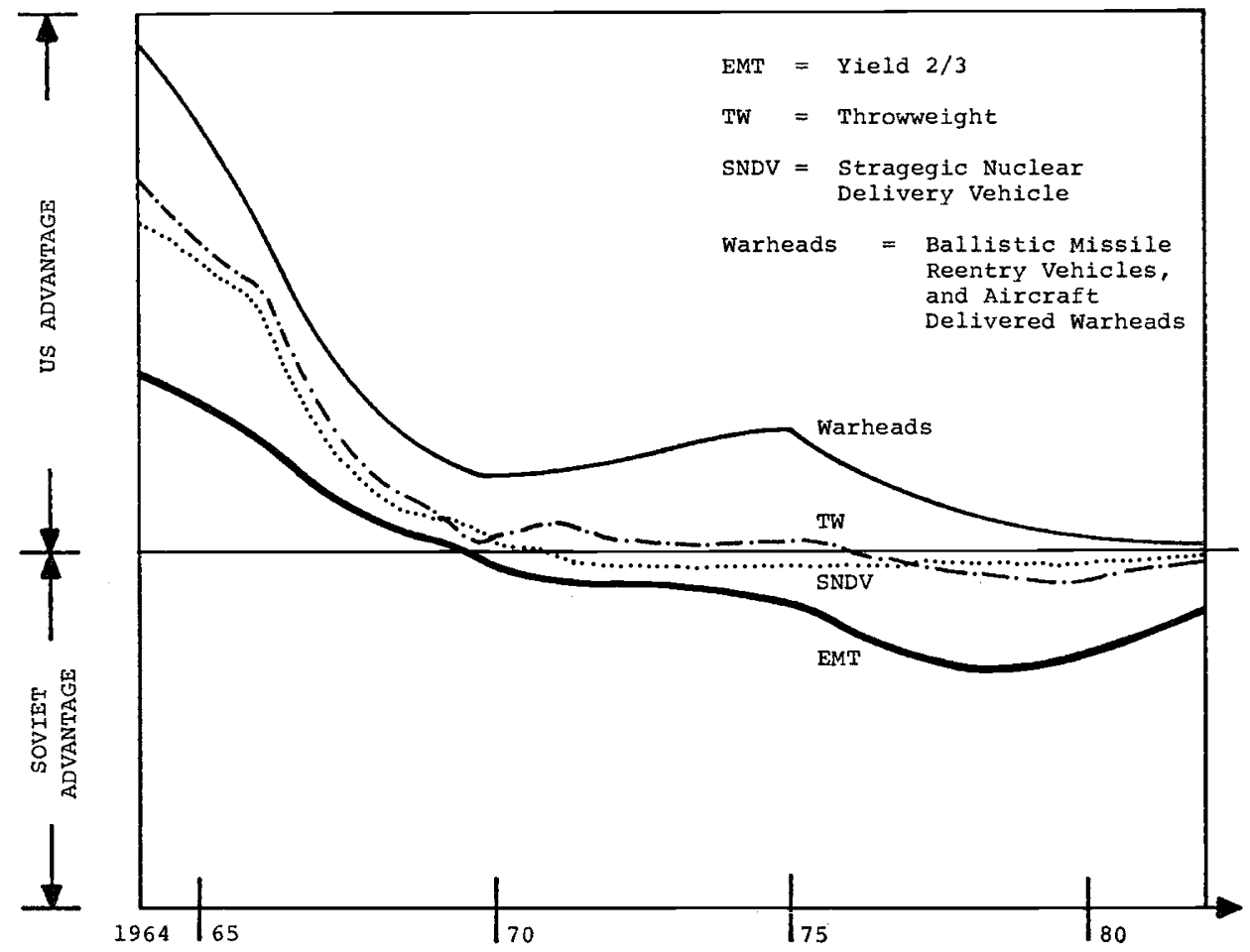

Let me also mention very briefly the United States' strategic programmes for the future: the new mobile land-based ICBM, called MK; the MK 12A warhead which is a very high yield warhead with great accuracy. (Accuracy of any kind of explosive is much more important as far as destructive effect is concerned than is yield. Destructive effect varies as the $2 / 3$ power of yield, but destructive effect of accuracy varies as the square of the distance from target.) The B-1 bomber is in abeyance for the moment, the Cruise Missile is under development, the Trident submarine is in series production as programmed. All these US strategic programmes may be accelerated or held in status quo, pending the outcome of further negotiations with the Soviet Union over the extensions of the 1972 Interim Agreement on Offensive Strategic Weapons, which expires October 1 this year.

The new SALT proposals put forward recently in Moscow by the United States were in two categories : one category was a proposal that the 1974 Vladivostok Accord, 
which limited both sides to 2400 strategic nuclear delivery vehicles, be reduced to treaty form and signed. That proposal was rejected by the Russians.

The other set of United States proposals was a very far reaching call for substantial reductions on both sides : strategic nuclear vehicles reduced from 2400 down to about 1900 , limitations on flight testing of new missiles, a ban on cruise missiles having a range in excess of $2500 \mathrm{~km}$, and certain assurances with regard to deployment and utilisation of the Russian Backfire bomber. All these proposals were designed and intended to preserve the invulnerability of the forces of both sides, and therefore to work in the direction of technical military stability. That is to say, the technical characteristics of the forces of both sides would not themselves, in a time of crisis, contribute to tension because of tempting vulnerability.

I do not think the Soviets are interested in things like technical stability. I think the Soviets look to their strategic nuclear forces for political effect. The Soviets continue to be interested in the competitive political effects of having a huge and dynamic programme - just as the communities of the middle ages expressed their aspirations, their skills, their strength, through the erection of magnificent cathedrals. I myself doubt that anything like the Carter proposals will be accepted by the Russians for a long time - probably during the Carter Presidency. That poses certain risks to the world. But then the Russian military build-up in Europe causes certain risks also.

What are those risks, and why worry about the Russian build-up in Europe? After all, NATO does have the capability to respond adequately to a Warsaw Pact attack. After all, the wars in the 19th and early part of the 20th century had what numerically was the greatest military establishment in the world; there was not anything like the worry that there is today over the Russian military build-up in Europe. Even the Soviets - after the collapse of the Russian army in World War I - by 1928 had rebuilt the Red Army so that again it was, numerically, the greatest military establishment in the world. Yet, it was not a source of great concern. Why is it a source of concern today?

There are three important geo-strategic differences between the situation then and the situation now.

1. World War II eliminated the military strength of Russia's two strongest neighbours and rivals - Germany and Japan. In the aftermath of World War II there was a power vacuum on both sides of the old Russian Empire.

2. As a result of World War II, the Russian military advance into Eastern and Central Europe gave to Russia for the first time in history a permanent military deployment in the very heart of Central Europe.

3. Moreover, the Russian economy, particularly Soviet military industry, was placed in intimate association with the sophisticated and advanced industrial and technological potential of Germany and Czechoslovakia. After several decades, that has been extremely important to the Russians, particularly in the fields of naval ship building, military electronics, and aircraft and missile design and construction.

During most of the time since World War II NATO - the West - has relied on two advantages:

1. Nuclear superiority, and 
2. Technological superiority.

Thus, although NATO at present does have the capability to respond adequately to a Warsaw Pack attack, the balance in the future may be less secure than it has been in the past. The immediate questions facing NATO - the risks - are not the old easy questions of numerical and qualitative comparisons of divisions, tanks, aircraft and the like. Rather they are hard questions, risky questions :

1. Is NATO prepared to respond on extremely short notice?

2. Could NATO actually carry out a surge in readiness in a crisis ?

3. How capable is NATO in making the transition from peace time to war time command and communications systems?

4. How vulnerable are our theater nuclear forces?

5. Has NATO adequately thought through how her forces and her governments would respond to possible Soviet probes on the northern or southern flanks of Europe ?

6. Is NATO organized to carry out such responses ?

The questions point to certain risks, but the real risk is that the competent NATO authorities may not ask and answer those questions with sufficient rigour. The situation may put at risk certain political positions, for example in Berlin. There has been in recent months a continuous pressure once again on Berlin. Chancelier Schmidt has said he would not repay a pin-brick with a pin-brick and that is a good attitude to have. But the question is : how many pin-bricks does it take to change the Four Power Status of Berlin? Western Europe, all of western Europe today, is characterized by weak minority governments. There is in the East a strong civil rights movement. Since Helsinki there has been a noticeable upsurge in so-called "Helsinki-Committees", and civil rights movements, all over eastern Europe, and not just in the Soviet Union. The combination of weakness in the West and pressures for change in the East is a risky combination.

Beyond Europe, the Soviets have developed a navy which has world-wide operating capabilities. It has a base near the Indian Ocean and very substantial fleet operations in the Indian Ocean on continuing basis. The Russians are quite active in Africa at the present time. They have a strong interest in the Persian Gulf - I have outlined that from the standpoint of the energy crisis. And there is a certain risk that the Soviets may underestimate either the interests of the West, or the willingness of the West to pursue and defend those interests, due to the lassitude which has been displayed over the last years or so. I must say, however, that the French in providing some support to Morocco and to Zaire are demonstrating a commendable sense of a strategy for dealing with those risks outside of Europe. It is a hopeful sign.

\section{Conclusion}

What can one conclude about appropriate strategies for coping with the risks and security problems with which states are faced today? One can read almost daily in the press that the world's resources are distributed inequitably : that $30 \%$ of the earth's population consume $70 \%$ of the earth's resources after having taken them away unfairly from $70 \%$ of the earth's population. What is left out of that accounting is the fact 
that the industrious $30 \%$ of the world, which consumes $70 \%$ of the earth's resources, live in a highly evolved culture which is so far the only culture that has demonstrated a capability to efficiency and effectively transform raw resources into food, machinery, fertilizer, and electricity. Without these, no part of the world can have any hope. Without that high culture, and without that capability, the world would be confronted with the risk of lurching into a disintegrative anticivilization that would be reminiscent of the Dark Ages.

Of course, these issues are not new. The original walls of Jericho, which were built ten thousand years ago, were built by farmers who had accumulated a surplus of grain which was the object of lustful and aggrandizing attention from desert warriors who did not have the capability of accumulating grain, and who wanted it for themselves. That is essentially what war has been about ever since : getting somebody else's surplus, or defending your surplus against somebody who could not provide one for himself.

Today we are faced with a whole range of very grave risks. We are going to have to change, and more rapidly rather than slowly. We are faced not just with an oil and economics crisis, not just a social and political crisis, not just a political-military crisis. One can say that several hours are striking simultaneously on the clock of history. We must face up to the great complex crisis. We must bring to bear the best of our rich and powerful heritage: the best of our intelligence, the best of our imagination, the best of our courage. But about all what is required is a sense and spirit of conviction. It is not exactly stylish in a lecture on strategy to talk about a spirit of conviction, but that is what is required : a conviction which manifests itself in a spirit of concern and engagement. We must go beyond tactics, we must go beyond economics, we must go beyond competition. We have to be clear about a system of values. We must be unambiguous about what our values are: it is only by holding and living according to a set of values that we can have strategies for coping with the trends in risk and security with which we are confronted in the present hour. 